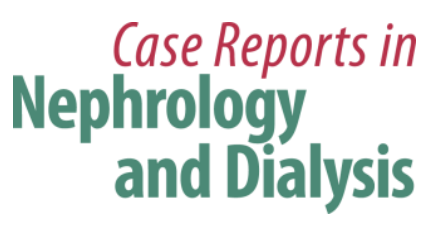

Case Rep Nephrol Dial 2016;6:21-25

DOI: $10.1159 / 000443728$

Publishea onine: February 3, 2016

(C) 2016 The Author(s)

Published by S. Karger AG, Basel

2296-9705/16/0061-0021\$39.50/0

www.karger.com/cnd

This article is licensed under the Creative Commons Attribution-NonCommercial 4.0 International License (CC BY-NC) (http://www.karger.com/Services/OpenAccessLicense). Usage and distribution for commercial purposes requires written permission.

\title{
Successful Image-Guided Retrieval of an Embolized Fragment of a Fractured Haemodialysis Catheter Tip from the Pulmonary Artery
}

\author{
Chia Wei Teoh $^{a} \quad$ Avnesh S. Thakor ${ }^{b} \quad$ Joao G. Amaral ${ }^{b} \quad$ Dimitri A. Parra $^{b}$ \\ Elizabeth A. Harvey ${ }^{a}$ Damien G. Noone ${ }^{a}$ \\ ${ }^{a}$ Division of Nephrology and ${ }^{b}$ Image-Guided Therapy, Department of Diagnostic Imaging, \\ The Hospital for Sick Children, University of Toronto, Toronto, Ont., Canada
}

\section{Key Words}

Paediatric nephrology · Interventional radiology · Dialysis · Embolism · Dialysis catheter · Diagnostic imaging $\cdot$ Renal medicine

\begin{abstract}
Background: Cuffed, double-lumen, tunneled haemodialysis catheters are a common means of vascular access in paediatric haemodialysis, particularly in infants. Haemodialysis catheter fracture with distal embolization is a rare complication. Case Report: A 2-year-old boy was receiving chronic haemodialysis via a right internal jugular cuffed, double-lumen, tunneled haemodialysis catheter, inserted 3 months previously. He was asymptomatic and was incidentally found to have had embolization of a fractured catheter tip into a segmental branch of the left pulmonary artery. The catheter was replaced and the embolized fragment successfully retrieved, non-surgically, using an image-guided endovascular approach with a loop snare device. Conclusion: Haemodialysis catheter fracture with distal embolization is a rare complication in both adults and children and is usually associated with prolonged use and catheter fatigue. Retrieval of the embolized fragment should always be attempted to prevent possible complications. Awareness of this potential complication is important to facilitate diagnosis and management.

(C) 2016 The Author(s)

Published by S. Karger AG, Basel
\end{abstract}

\section{KARGER}

Chia Wei Teoh, MB, BCh, BAO, MRCPI, LRCSI

Division of Nephrology, The Hospital for Sick Children

University of Toronto

555 University Avenue, Toronto, ON M5G1X8 (Canada)

E-Mail chiawei.teoh@sickkids.ca 


\section{Case Reports in \\ Nephrology \\ and Dialysis}

Case Rep Nephrol Dial 2016;6:21-25

DOI: $10.1159 / 000443728$

(C) 2016 The Author(s). Published by S. Karger AG, Basel www.karger.com/cnd

Teoh et al.: Successful Image-Guided Retrieval of an Embolized Fragment of a Fractured Haemodialysis Catheter Tip from the Pulmonary Artery

\section{Introduction}

Haemodialysis requires a means of providing repeated, secure access to the bloodstream whilst ensuring an adequate rate of blood flow. Cuffed, double-lumen, tunneled haemodialysis catheters are a common means of vascular access in paediatric haemodialysis, as connection to the dialysis circuit is straightforward and needle-free [1] and the access is immediately useable after insertion.

Disadvantages and shortcomings of prolonged catheter use include thrombotic occlusion, either by thrombus or fibrin sheath [2,3], catheter-related infection [4], malposition or migration [5]. Haemodialysis catheter fracture with distal embolization is a rare complication. We report a case of pulmonary arterial embolization of a fractured haemodialysis catheter tip in a paediatric patient, successfully retrieved via an image-guided, endovascular technique.

\section{Case Report}

A 10-kg, 2-year-old boy with autosomal recessive polycystic kidney disease was receiving chronic haemodialysis 6 days per week through a 10-Fr double lumen, tunneled HemoCath $^{\circledR}$ (MedCOMP ${ }^{\circledR}$, Harleysville, Pa., USA), inserted in his right internal jugular vein 3 months previously. He was asymptomatic when a routine chest X-ray, performed prior to a planned living donor kidney transplant, revealed embolization of a fractured catheter tip into a branch of the left pulmonary artery (fig. 1). There were no episodes of catheter dysfunction, thrombosis, line manipulation or infection. No crack or fracture was observed in the external portion of the catheter. The timing and reason for catheter tip fracture was unclear.

In view of the upcoming transplant and need for lifelong immunosuppressive therapy, a decision was made to attempt extraction of the embolized tip. Interventional radiology replaced the catheter and removed the embolized fragment from a segmental branch of the left pulmonary artery using an image-guided endovascular approach with a loop snare device (fig. 2), via right femoral access.

\section{Discussion}

Embolization of a fractured haemodialysis catheter tip is a relatively rare, and usually late, complication of tunneled central venous catheter (CVC) placement [6-8]. It occurs more commonly with the subclavian approach, and the 'pinch-off sign' may herald catheter fracture - where the catheter narrows as it travels over the first rib and underneath the clavicle $[8,9]$. However, catheter fracture can also occur when the CVC is placed via an internal jugular approach [10]. Cases involving catheter tip fracture of dialysis catheters are rare, but in 2 reported adult patients, both were symptomatic $[6,7]$. One of them presented with cough, haemoptysis and right-sided pleuritic chest pain [6], while the other had cough, decreased appetite and small amounts of sputum production [7]. One previous report of this complication in 2 children with non-dialysis CVCs involved larger fragments that remained in the heart, and likely involved the 'pinch-off syndrome' $[8,11,12]$. The true incidence of embolization of the fractured distal segment of haemodialysis catheters is unknown. 


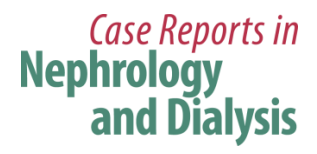

Teoh et al.: Successful Image-Guided Retrieval of an Embolized Fragment of a Fractured Haemodialysis Catheter Tip from the Pulmonary Artery

Catheter fracture may be symptomatic with intermittent catheter malfunction, increased resistance to fluid administration, persistent coughing, chest pain and palpitations [7], but may also be asymptomatic as in our patient.

The cause of the catheter tip fracture in our patient remains unclear. Follow-up chest radiographs immediately after insertion showed no kinking and confirmed an acceptable position of the tip at the cavo-atrial junction. There were no problems with inadequate blood flow during dialysis runs and no episodes of thrombosis or infection. There was no manipulation, such as stripping or adjustment of the catheter after placement. Our patient was asymptomatic and the catheter tip fracture and distal embolization only became apparent on a routine pre-operative chest radiograph. Despite the fracture, the catheter tip was still positioned in the right atrium (fig. 1), which suggests inward migration of the catheter after insertion. The fracture was at the distal (venous) tip of the catheter at the junction of the two lumens unlike most cases reported previously in the literature, which occurred more proximally. These findings led us to speculate that the distal migration of the catheter may have led to repeated kinking or bending of the catheter tip, compromising its integrity with eventual fracture of the tip.

Many haemodialysis catheters are designed with a stepped tip to reduce recirculation. This additional length at the tip between the openings of the proximal and distal lumens makes it difficult to accurately place both lumens at the cavo-atrial junction in infants and young children. Often, the more distal tip lies deep within the right atrium. This potentially predisposes the catheter tip to fracture due to repeated kinking or bending.

The fractured tip can embolize distally anywhere along the blood flow tract, but typically will remain either in the heart, or the pulmonary vasculature, as in our patient [13]. Other reported complications include myocardial or valvular rupture, vascular perforation, arrhythmias, thrombus formation, infection, infective endocarditis and pulmonary abscess $[6,7]$.

Although there have been reported cases in which the fractured catheter tip remained in the patients' pulmonary vasculature without complications [14], we advocate that retrieval of the embolized tip should be attempted to prevent possible complications. This can be via a non-surgical, percutaneous approach using a loop-snare device as described in our patient, or may require a surgical approach if the tip has become embedded or fixed due to fibrosis.

Cuffed, double-lumen, tunneled haemodialysis catheters are a common means of vascular access in children requiring haemodialysis. Our patient highlights a rare complication of haemodialysis catheter use that could potentially lead to devastating consequences for the patient. It is therefore important that nephrologists looking after these patients have an awareness of this complication to facilitate diagnosis and management.

\section{Statement of Ethics}

The authors have no ethical conflicts to declare.

\section{Disclosure Statement}

The authors have no conflicts of interest to declare. 
Teoh et al.: Successful Image-Guided Retrieval of an Embolized Fragment of a Fractured Haemodialysis Catheter Tip from the Pulmonary Artery

\section{References}

1 Atherikul K, Schwab SJ, Conlon PJ: Adequacy of haemodialysis with cuffed central-vein catheters. Nephrol Dial Transplant 1998;13:745-749.

-2 Teoh CW, Bates M, Cotter M, Quinlan C, Dolan NM, Riordan M, et al: Recombinant tissue plasminogen activator is safe and effective in increasing haemodialysis catheter longevity in paediatric haemodialysis patients. J Nephrol Ther 2014;4:2012-2015.

-3 Peel RK, Turney JH: Fibrin sheath on a tunnelled haemodialysis catheter. Nephrology Dialysis Transplantation 2003;18:1026.

4 Allon M: Dialysis catheter-related bacteremia: treatment and prophylaxis. Am J Kidney Dis 2004;44:779791.

5 Skandalos I, Hatzibaloglou A, Evagelou I, Ntitsias T, Samaras A, Visvardis G, et al: Deviations of placement/function of permanent central vein catheters for hemodialysis. Int J Artif Org 2005;28:583-590.

-6 Sagar V, Lederer E: Pulmonary embolism due to catheter fracture from a tunneled dialysis catheter. Am J Kidney Dis 2004;43:e13-e14.

7 Chawla LS, Chegini S, Thomas JW, Guzman NJ: Hemodialysis central venous catheter tip fracture with embolization into the pulmonary artery. Am J Kidney Dis 2001;38:1311-1315.

-8 Mirza B, Vanek VW, Kupensky DT: Pinch-off syndrome: case report and collective review of the literature. Am Surg 2004;70:635-644.

-9 Aitken DR, Minton JP: The 'pinch-off sign': a warning of impending problems with permanent subclavian catheters. Am J Surg 1984;148:633-636.

10 Shimizu A, Lefor A, Nakata M, Mitsuhashi U, Tanaka M, Yasuda Y: Embolization of a fractured central venous catheter placed using the internal jugular approach. Int J Surg Case Rep 2014;5:219-221.

11 Tutar E, Aypar E, Atalay S, Yavuz G, Dogu F: Percutaneous transcatheter retrieval of intracardiac central venous catheter fragments in two infants using Amplatz Goose Neck snare. Turk J Pediatr 2009;51:519-523.

-12 Hinke DH, Zandt-Stastny DA, Goodman LR, Quebbeman EJ, Krzywda EA, Andris DA: Pinch-off syndrome: a complication of implantable subclavian venous access devices. Radiology 1990;177:353-356.

-13 Fuenfer MM, Georgeson KE, Cain WS, Colvin EV, Johnson WH Jr, Pearce FB, et al: Etiology and retrieval of retained central venous catheter fragments within the heart and great vessels of infants and children. J Pediatr Surg 1998;33:454-456.

14 Reynen K: 14-year follow-up of central embolization by a guidewire. N Engl J Med 1993;329:970-971.

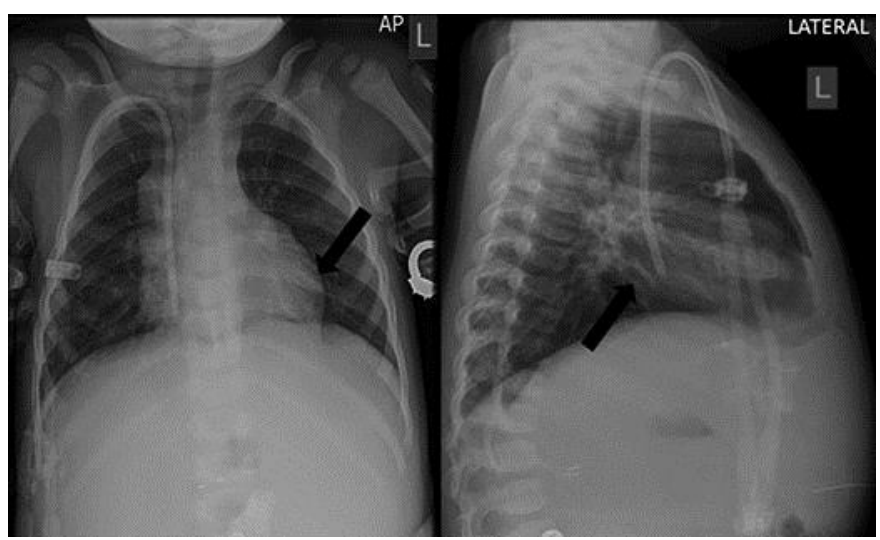

Fig. 1. A chest radiograph showing the embolized fractured fragment of the haemodialysis catheter in a segmental branch of the left pulmonary artery (black arrow). 


\section{Case Reports in \\ Nephrology \\ and Dialysis}

\begin{tabular}{l|l}
\hline Case Rep Nephrol Dial 2016;6:21-25 \\
\hline DOI: $10.1159 / 000443728$ & $\begin{array}{l}\text { (c) } 2016 \text { The Author(s). Published by S. Karger AG, Basel } \\
\text { www.karger.com/cnd }\end{array}$ \\
\hline
\end{tabular}

Teoh et al.: Successful Image-Guided Retrieval of an Embolized Fragment of a Fractured Haemodialysis Catheter Tip from the Pulmonary Artery

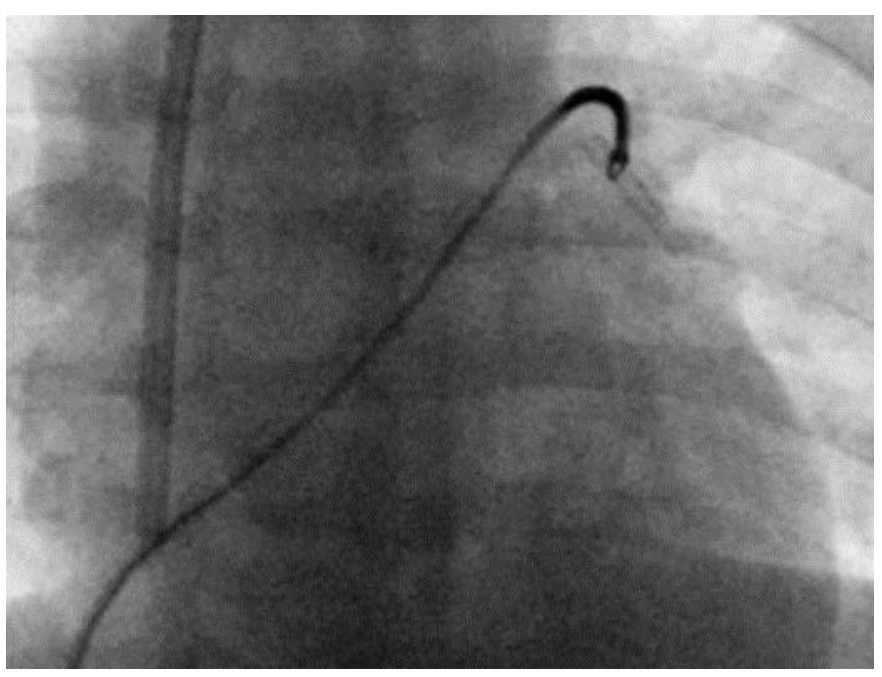

Fig. 2. Removal of the embolized fragment of the haemodialysis catheter from a segmental branch of the left pulmonary artery via an endovascular approach using a loop snare device. 